\title{
Pengenalan Pengaruh SuaraKonsonan Terhadap Vokal Menggunakan MFCC dan SVM
}

\author{
Muhammad Makmun Effendi \\ STT Pelita Bangsa \\ effendiyanegmail.com
}

\begin{abstract}
Abstrak - Suara merupakan alat komunikasi paling mendasar bagi manusia. Saat ini, suara tidak hanya digunakan untuk komunikasi antar manusia tetapi juga digunakan untuk berkomunikasi dengan perangkatperangkat teknologi, oleh sebab itu topik pengenalan suara semakin berkembang. Penelitian yang dilakukan adalah untuk menyederhanakan pengenal ucapan yang bertujuan untuk mengenali pengaruh konsonan terhadap vokal dengan memanfaatkan informasi disekitar ucapan konsonan dan vokal tersebut. Metode Penelitian yang digunakan dalam membangun sistem pengenalan suara ini berdasarkan konsonan yang telah di pengaruhi oleh vokal dengan menggunakan MFCC (Mel-frequency cepstrum coefficients) dan SVM (Support Vektor Machine) algoritma. Hal yang dilakukan untuk mengenali konsonan dengan cara merekam suara vokal terlebih dahulu dan setelah itu merekam konsonan dari beberapa orang dan hasil rekamannya dicatat dan dilatih mengetahui seberapa besar konsonan terhadap vokal dapat dikenali.
\end{abstract}

\section{PENDAHULUAN}

Manusia merupakan mahkluk individu yang terbiasa hidup berkelompok dan bersosialisasi, sehingga untuk berinteraksi antara manusia satu dengan manusia yang lainnya di butuhkan suatu komunikasi, sedangkan definisi komunikasi itu sendiri adalah suatu proses dimana dua orang atau lebih saling bertukar suatu informasi, saling memberikan pengaruh satu sama lain, baik itu disengaja maupun tidak disengaja. (Shannon \& Weaver).

Komunikasi dapat dilakukan dengan berbagai cara diantaranya melalui percakapan, bahasa verbal, mimik muka, gambaran atau lukisan,karya seni, ataupun tekhnologi. Seiring kemajuan zaman dimana teknologi semakin berkembang, maka manusia tidak hanya berinteraksi dengan manusia saja, tetapi seringkali juga harus berinteraksi dengan perangkat-perangkat teknologi. Saat ini belum banyak perangkat teknologi yang mampu mengenali bahasa lisan manusia. Ini disebabkan oleh sulitnya perangkat teknologi menangkap pesan lisan, lalu menterjemahkannya dan akhirnya menjalankan perintah yang terkandung dalam pesan lisan tersebut.

Untuk kepentingan itu, tentu dibutuhkan perangkat tambahan yang mencakup teknologi pengenalan suara.Penelitian dibidang pengenalan ucapan otomatis (Automatic Speech Recognition) merupakan salah satu riset yang banyak ditekuni dan terus dikembangkan hingga saat ini. Riset tersebut telah diteliti dan dikembangkan sejak lebih dari empat dekade lalu (Rabiner dan Juang, 1993).

Salah satu tujuan dari pengembangannya adalah untuk menciptakan era baru dalam interaksi antara manusia dengan komputer, yang selama ini lebih banyak dilakukan dengan tangan atau jari, menjadi lebih mudah dengan hanya mengucapkan suatu kata atau kalimat tertentu.Pada Penelitian yang dilakukan adalah dari pengembangan sistem pengenalan ucapan otomatis dengan pendekatan baru, walaupun metode yang digunakan adalah metode lama yaitu MFCC dan SVM.

Ide dasar dari penelitian ini adalah jauh lebih mudah mengenali vokal dari pada konsonan karena itu kenapa tidak dimanfaatkan saja untuk pengenalan ucapan berdasarkan vokal. Misalnya kalimat yang mau dikenali adalah "ibu pergi ke pasar" karena yang dikenalinya hanya vokal maka hasilnya adalah i,u,e,i,e,a,a. Untuk hubungan suku katanya, jika diambil kata "ibu" itu terdiri huruf vokal "i" dan "u" , maka bisa berasal dari "ibu', "itu","isu", dari hal itulah maka penelitian ini dilakukan untuk mengetahui peran dari konsonan, karena tujuan dari penelitian ini untuk mengenali konsonan-konsonan tersebut dengan cara merekap dan suku kata, karena sulit untuk merekam konsonan. Konsonan itu akan di peroleh dengan mengurangi dari depan ataupun dari belakang huruf vokal.

Pengenalan suara konsonan orang untuk penelitian ini dilakukan dengan menggunakan Mel-Frequency Cepstral Coefficient (MFCC), dan 


\section{IT FOR SOCIETY, Vol. 03, No. 02}

ISSN 2503-2224

SVMuntuk membantu manusia dalam berkomunikasi tanpa harus mengkhawatirkan adanya perbedaan kultur, aksen dan cara berbahasa.

Dari beberapa penelitian di atas dapat dilihat bahwa terdapat perbedaan pada hasil akurasi dari masing-masing metode. Hal ini disebabkan karena perbedaan parameter yang digunakan dalam pengujian yang dilakukan seperti sumber data yang berbeda, banyak data yang berbeda dan banyak iterasi yang berbeda untuk pelatihan pada masing masing metode, sehingga sulit untuk menentukan metode mana yang lebih baik dalam melakukan penelitian ini.

Batasan masalah dalam penelitian ini agar tidak melebar dan juga lebih terarah, maka batasan masalahnya adalah sebagai berikut:

- Responden diambil dari beberapa orang dewasa (sampel kedua dan sampel ke satu)

- Data masukan untuk pemodelan dan pembelajaran algoritma MFCF(MelFrequency Cepstrum Coefficient) konsonan yang diambil dari responden dan masing masing responden diambil datanya sebagai contoh ucapan untuk setiap runtun kata

- Data yang digunakan untuk pengujian dari contoh ucapan untuk setiap runtun kata. Ucapan yang direkam untuk pelatihan serta pengujian data pelatihan, sedangkan ucapan lainnya untuk pengujian data di luar data pelatihan, serta tambahan ucapan rekaman untuk pengujian ucapan rekaman langsung.

- Metode klasifikasi suara konsonan sebagai data pembelajaran dan pengujian menggunakan SVM (Support Vector Machine).

- Metode MFCC digunakan untuk proses pengenalan ucapan.

- Ucapan dikenali dapat berupa Bahasa asing, bahasa daerah, bahasa Indonesia, namun diprioritaskan dalam penelitian ini menggunakan bahasa Indonesia yang memiliki suku kata konsonan-vokal.

Adapun penelitian ini dilakukan bertujuan utama untuk mengetahui peran konsonan dan mengenali pengaruh konsonan terhadap vokal dengan cara terlebih dahulu merekam vokal. Hal ini dilakukan karena untuk merekam konsonan sangat sulit dibandingkan dengan vokal.

Pada penelitian sebelumnya telah ada penelitian yang hampir serupa yaitu penelitian tentang pengenalan fonem contohnya pada kata "raba" dan "laba" kedua kata tersebut mirip mempunyai 4 bunyi suara, perbedaaanya adalah pada bunyi suara pertama dan contoh lainnya seperti kata "teras" dengan "teras" kedua kata itu memiliki huruf yang sama namun ketika diucapkan dan dilanjutkan dengan kalimat yang mengikutinya maka artinya akan berbeda, yang membedakannya adalah pada pengucapan "te" dan "TE'. Untuk penelitian yang dilakukan peneliti saat ini berbeda dengan penelitian tersebut. Penelitian disini adalah penelitian terhadap pengenalan pengaruh suara konsonan terhadap vokal, sebagai contoh pada kata "ibu", jika diganti dengan kata "itu" maka artinya akan berbeda, disini yang akan diteliti adalah suku kata "bu" dan "tu" yang sama sama mempunyai vokal "u", pengaruh konsonan ("b" dan 't") terhadap vokal ('u) itulah yang akan diukur perbedaannya didalam penelitian ini, perbedaan tersebut itu yang bisa digunakan untuk mengenali/membedakan konsonan "b" dan " $t$ ". Untuk itulah peneliti ingin melakukan penelitian yang lebih mendalam pada materi tersebut, dengan menggunakan metode MFCC (Mel-frequency cepstrum coefficients) dan SVM(Support Vector Machine) .

\section{METODOLOGI PENELITIAN}

Metode atau langkah-langkah yang akan digunakan dalam penelitian yaitu sebagai berikut:

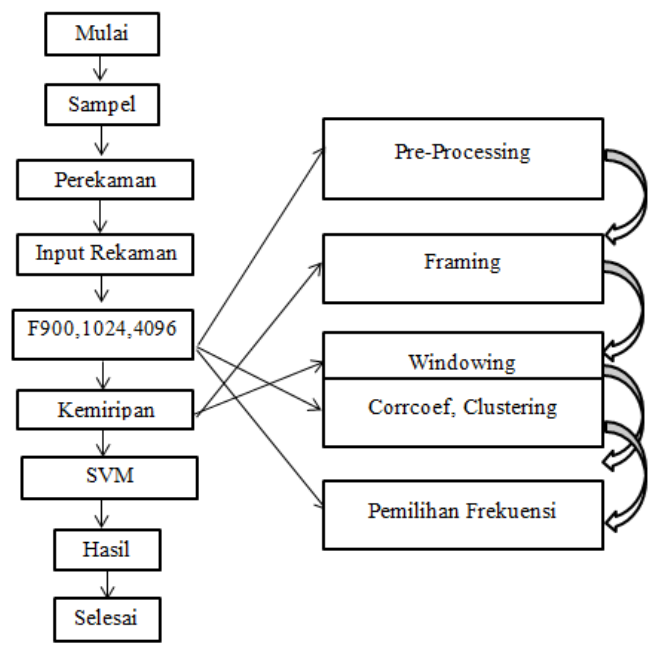

Gambar 1. Tahapan Penelitian

1. Mulai

Peneliti melakukan persiapan penelitian berupa bahan, perlengkapan dan peralatan yang akan digunkan dalam penelitian.

2. Sampel

Peneliti memnentukan orang yang akan direkam 3. Perekaman

Peneliti melakukan proses rekaman suara dari 3 orang sampel.

4. Ekstraksi Ciri

Merupakan suatu tahapan dimana peneliti mengekstrak ciri atau informasi dari data sampel yang didapat agar data bisa dikenali/ dibedakan sesuai jenisnya

5. MFCC 
Untuk Proses rekaman menggunakan matlab versi 2013 dengan metode MFCC. Tahapan tahapannya adalah sbb :

a. Pra-proses

Tahap ini sering kali disebut juga dengan preemphasis karena merupakan dimana sinyal dilewatkan melalui sebuah filter untuk menekan pada frekuensi agar lebih tinggi.

b. Windowing

Peneliti menggunakan Hamming window sebagai jalan yang dapat mempertimbangkan blok selanjutnya dalam rantai ekstraksi fitur dan meminimalkan lemahnya sinyal pada suara dari bagian awal sampai akhir

c. Fast Fourier Transform

Tahap ini mengubah masing-masing $\mathrm{N}$ sampel Frame dari Domain waktu menjadi domain Frekuensi.

d. Mel Filter bank Processing

Proses ini dilakukan untuk menghitung nilai Mel dalam satuan frekuensi.

e. Discrete Cosine Transform

Tahap ini peneliti melakukan sebuah proses untuk mengubah log Mel Spektrum menjadi domain waktu dengan menggunakan Discrete Cosine Transform (DCT) dan hasil dari proses akhir disebut dengan MFCC (Mel Frequency Cepstrum Coefficient)

6. Ekstraksi ciri/ Proses Pemilihan Fitur

adalah tahapan dimana peneliti melakukan proses pemisahan berdasarkan jenis ataupun kesamaan.

Data yang didapat dalam proses ini adalah data frekuensi dan data koeefisien korelasi.

7. Metode Klasifikasi

Pada Penelian ini peneliti menggunakan Perangkat lunak Minitab toolsuntuk mencari kemiripan konsonan dengan metode analisis cluster.

Data frekuensi konsonan dikelola menggunakan minitab dengan memilih menu multivariant yang ada pada minitab, setelah itu minitab akan menghasilkan data, dari data tersebut peneliti melakukan analisis kemiripan huruf huruf vokal yang di pengaruhi oleh konsonan.

Setelah itu peneliti juga melakukan klasifikasi dengan menggunakan Support Vektor Machine (SVM), Set fitur yang telah diekstraksi sebelumnya digunakan pada tahap ini untuk membedakan tingkat suara orang. Hal yang pertama dilakukan adalah melatih classifier dengan beberapa input file pengucapan huruf vokal konsonan disertai dengan proses pelabelan. Algoritma ini membuahkan hyper plane yang dapat dikategorikan sampel baru.

\section{HASIL PENELITIAN}

Pada penelitian ini peneliti telah memilih untuk mengidentifikasi beberapa suara orang dewasa untuk melakukan rekaman suara pada huruf koefisien korelasi konsonan terhadap vokal sebagai bahan penelitiannya.

Tabel 3.1 Jumlah huruf vokal dan konsonan

\begin{tabular}{|c|l|c|}
\hline No & Keterangan & Jumlah Huruf \\
\hline 1 & Huruf Vokal & 6 \\
\hline 2 & Huruf Konsonan & 21 \\
\hline 3 & $\begin{array}{l}\text { Huruf kombinasi Konsonan terhadap } \\
\text { vokal }\end{array}$ & 105 \\
\hline
\end{tabular}

Dari Tabel 3.1 bisa dilihat bahwa untuk masingmasing sampel akan mengucapakan 105 huruf kombinasi konsonan terhadap vokal. dan untuk masing-masing huruf vokal peneliti melakukan 5 kali atau $15 \mathrm{x}$ pengulangan pengucapan rekaman, Untuk menghitung jumlah hasil keseluruhan rekaman dari semua sampel peneliti melakukan langkah berikut:

\begin{tabular}{|c|c|}
\hline Data Frekuensi dan Koefisien & en Korelasi dengan pengucapan 5 kali pengulangan \\
\hline & Data K \\
\hline$=3150 \times 3=945$ & Data Koefisien Korelasi untuk 3 orang \\
\hline$=630 \times 4097$ & Data Frekuensi konsonan vokal 1 orang \\
\hline$=8190 \times 4097 \rightarrow$ & Data Frekuensi konsonan vokal 3 orang \\
\hline 4097 & Data Frekuensi Vokal 1 orang \\
\hline$=3 \times 30=90 \times 4097 \longrightarrow$ & Data Frekuensi Vokal 3 orang \\
\hline$=189$ & \\
\hline
\end{tabular}

\subsection{Proses Ekstraksi Fitur}

Merupakan suatu tahapan untuk mengekstrak ciri atau informasi dari data sampel yang didapat agar data bisa dikenali/ dibedakan sesuai jenisnya

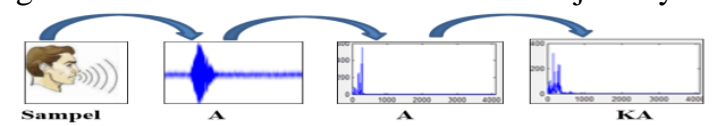

Gambar 2. Ekstraksi fitur
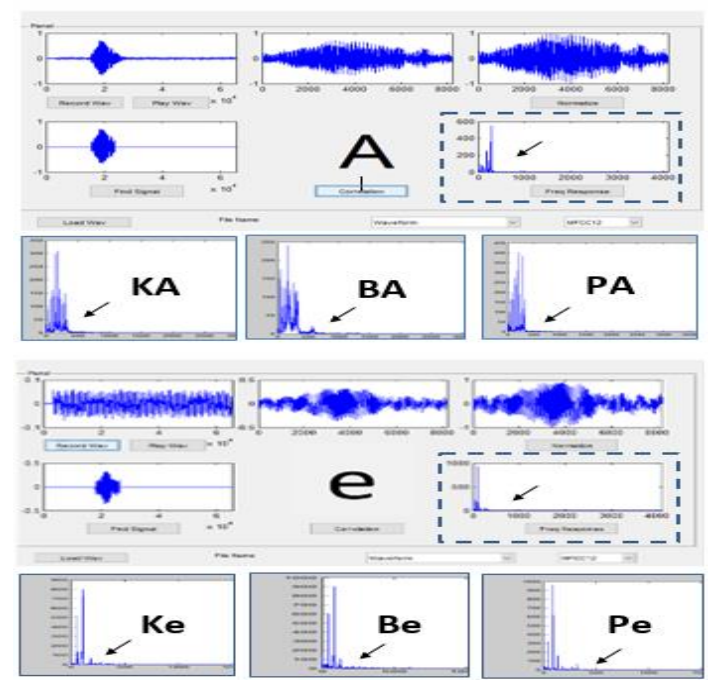

Gambar 3. Pengaruh konsonan terhadap huruf vokal

Hasil gambar 3. pengaruh konsonan terhadap huruf vokal "A" pada pria setelah dipengaruhi oleh konsonan ' $\mathrm{K}$ ', 'P' dan 'B' maka ada perubahan yang terjadi pada frekuensi responds, sehingga 


\section{IT FOR SOCIETY, Vol. 03, No. 02} ISSN 2503-2224

sinyal secara visual dapat dilihat perbedaannya. Begitu juga huruf vokal 'e' yang dipengaruhi konsonan 'B',P dan ' $\mathrm{K}$ ' pada suara pria juga dapat dikenali. Sedangkan, pengaruh konsonan terhadap huruf vokal "A" pada wanita setelah dipengaruhi oleh konsonan ' $\mathrm{K}$ ', ' $\mathrm{P}$ ' dan ' $\mathrm{B}$ ' maka ada perubahan yang terjadi pada frekuensi responds, sehingga sinyal secara visual dapat dilihat perbedaannya. Begitu juga huruf vokal 'e' yang dipengaruhi konsonan ' $\mathrm{B}$ ', $\mathrm{P}$ dan ' $\mathrm{K}$ ' pada suara wanita juga dapat dikenali.

\subsection{Koefisien Korelasi}

Untuk melihat korelasi pengaruh konsonan terhadap vokal maka peneliti menghitung nilai koefisien korelasi menggunakan matlab. Adapun Spektrum dan hasil koefisien korelasi yang ditampilkan disini untuk pria yang telah dipengaruhi konsonan adalah sebagai berikut:
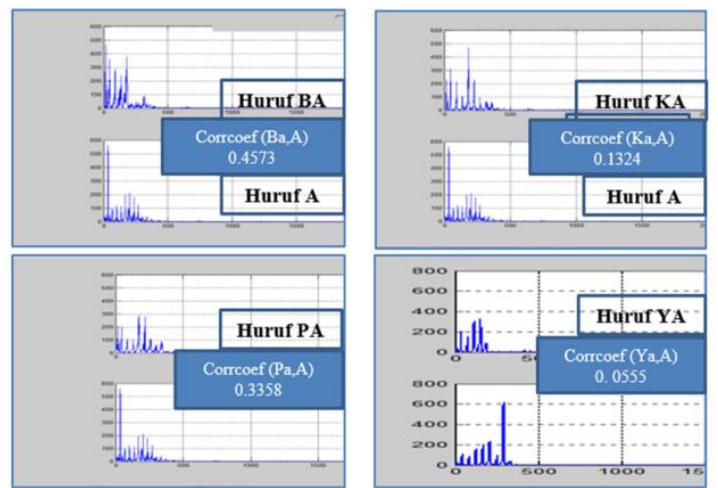

Gambar 4. Sinyal Corrcoef Pengaruh konsonan terhadap vokal Pada Pria

\subsection{Klasifikasi}

Klasifikasi dilakukan dengan analisis cluster, untuk menentukan kemiripan dari pengaruh konsonan terhadap vokal dengan menggunakan minitab tool.

Hasil cluster pada minitab pada kolom cluster joined terlihat kemiripan masing masing pengaruh konsonan terhadap vokal, pada cluster joined696 (Ra) mirip dengan 698(Ra), begitu juga 1006(VE) mirip dengan 1026(QE), selanjutnya 696 (Ra) mirip dengan 1006(QE), sehingga bisa dikatakan 696(Ra) jaraknya berdekatan dengan 698(Ra) dan juga berdekatan dengan 1006(VE).

Kemudian peneliti juga melakukan klasifikasi data frekuensi menggunkan SVM untuk mengetahui accuracy validation. Hasil dari SVM yang didapat dari masing masing parameter adalah sebagai berikut :

Hasil SVM dengan menggunakan Cross Validation Accuracy pada matlab untuk tiga orang dengan pengulangan $5 \mathrm{x}$ dan hasil yang didapat untuk pengaruh konsonan terhadap vokal yang paling tinggi adalah $37,037 \%$ dan yang terendah adalah $26.6138 \%$, sedangkan hasil vokalnya adalah $67.78 \%$.
Hasil SVM dengan menggunakan Cross Validation Accuracy pada matlab untuk sepuluh orang dengan pengulangan pengucapan 5x,hasil tertinggi yang didapat untuk pengaruh konsonan terhadap vokal adalah $36,7460 \%$, dan yang terendah adalah $30.6508 \%$.

Hasil SVM dengan menggunakan Cross Validation Accuracy pada matlab untuk sepuluh orang dengan pengulangan pengucapan $15 \mathrm{x}$, hasil tertinggi yang didapat untuk pengaruh konsonan terhadap vokal adalah 49,6473\%, dan yang terendah adalah $42.7513 \%$.

Hasil rekaman dengan menggunakan web speech API didapatkan sebagai berikut:

Tabel 3.2 Rekaman Web Speech API

\begin{tabular}{|c|c|c|c|c|c|c|c|c|c|}
\hline $\begin{array}{l}\mathrm{N} \\
\mathrm{O}\end{array}$ & Kata & $\begin{array}{c}\text { Org } \\
1 \\
\end{array}$ & $\begin{array}{l}\text { Or } \\
\mathrm{g} 2\end{array}$ & $\begin{array}{l}\text { Or } \\
\text { g } 3\end{array}$ & $\begin{array}{l}\text { Or } \\
\text { g } 4\end{array}$ & $\begin{array}{l}\text { Or } \\
\text { g } 5\end{array}$ & $\begin{array}{l}\text { Or } \\
\text { g } 6\end{array}$ & $\begin{array}{l}\text { Or } \\
\mathrm{g} 7\end{array}$ & $\begin{array}{l}\text { Rasio } \\
\text { Benar }\end{array}$ \\
\hline 1 & Apa & Yes & $\begin{array}{c}\mathrm{Ye} \\
\mathrm{s}\end{array}$ & $\begin{array}{c}\mathrm{Ye} \\
\mathrm{s}\end{array}$ & $\begin{array}{c}\mathrm{Ye} \\
\mathrm{s}\end{array}$ & $\begin{array}{c}\mathrm{Ye} \\
\mathrm{s}\end{array}$ & $\begin{array}{c}\mathrm{Ye} \\
\mathrm{s}\end{array}$ & $\begin{array}{c}\mathrm{Ye} \\
\mathrm{s}\end{array}$ & $100 \%$ \\
\hline 2 & Ibu & Yes & $\begin{array}{c}\mathrm{Ye} \\
\mathrm{s}\end{array}$ & $\begin{array}{c}\mathrm{Ye} \\
\mathrm{s}\end{array}$ & $\begin{array}{c}\mathrm{Ye} \\
\mathrm{s}\end{array}$ & $\begin{array}{c}\mathrm{Ye} \\
\mathrm{s}\end{array}$ & $\begin{array}{c}\mathrm{Ye} \\
\mathrm{s}\end{array}$ & $\begin{array}{c}\mathrm{Ye} \\
\mathrm{s}\end{array}$ & $100 \%$ \\
\hline 3 & Asi & Yes & No & $\begin{array}{c}\mathrm{Ye} \\
\mathrm{s}\end{array}$ & No & No & No & $\begin{array}{c}\mathrm{Ye} \\
\mathrm{s}\end{array}$ & $\begin{array}{c}42.85 \\
\%\end{array}$ \\
\hline 4 & Itu & Yes & $\begin{array}{c}\mathrm{Ye} \\
\mathrm{s}\end{array}$ & $\begin{array}{c}\mathrm{Ye} \\
\mathrm{s}\end{array}$ & $\begin{array}{c}\mathrm{Ye} \\
\mathrm{s}\end{array}$ & $\begin{array}{c}\mathrm{Ye} \\
\mathrm{s}\end{array}$ & $\begin{array}{c}\mathrm{Ye} \\
\mathrm{s}\end{array}$ & $\begin{array}{c}\mathrm{Ye} \\
\mathrm{s}\end{array}$ & $100 \%$ \\
\hline 5 & Isu & Yes & $\begin{array}{c}\mathrm{Ye} \\
\mathrm{s}\end{array}$ & $\begin{array}{c}\mathrm{Ye} \\
\mathrm{s}\end{array}$ & $\begin{array}{c}\mathrm{Ye} \\
\mathrm{s}\end{array}$ & $\begin{array}{c}\mathrm{Ye} \\
\mathrm{s}\end{array}$ & $\begin{array}{c}\mathrm{Ye} \\
\mathrm{s}\end{array}$ & $\begin{array}{c}\mathrm{Ye} \\
\mathrm{s}\end{array}$ & $100 \%$ \\
\hline 6 & Joko & Yes & $\begin{array}{c}\mathrm{Ye} \\
\mathrm{s}\end{array}$ & $\begin{array}{c}\mathrm{Ye} \\
\mathrm{s}\end{array}$ & $\begin{array}{c}\mathrm{Ye} \\
\mathrm{s}\end{array}$ & $\begin{array}{c}\mathrm{Ye} \\
\mathrm{s}\end{array}$ & $\begin{array}{c}\mathrm{Ye} \\
\mathrm{s}\end{array}$ & $\begin{array}{c}\mathrm{Ye} \\
\mathrm{s}\end{array}$ & $100 \%$ \\
\hline 7 & Susu & Yes & $\begin{array}{c}\mathrm{Ye} \\
\mathrm{s}\end{array}$ & $\begin{array}{c}\mathrm{Ye} \\
\mathrm{s}\end{array}$ & $\begin{array}{c}\mathrm{Ye} \\
\mathrm{s}\end{array}$ & $\begin{array}{c}\mathrm{Ye} \\
\mathrm{s}\end{array}$ & $\begin{array}{c}\mathrm{Ye} \\
\mathrm{s}\end{array}$ & $\begin{array}{c}\mathrm{Ye} \\
\mathrm{s}\end{array}$ & $100 \%$ \\
\hline 8 & Papa & No & No & $\begin{array}{c}\mathrm{Ye} \\
\mathrm{s}\end{array}$ & $\begin{array}{c}\mathrm{Ye} \\
\mathrm{s}\end{array}$ & $\begin{array}{c}\mathrm{Ye} \\
\mathrm{s}\end{array}$ & $\begin{array}{c}\mathrm{Ye} \\
\mathrm{s}\end{array}$ & $\begin{array}{c}\mathrm{Ye} \\
\mathrm{s}\end{array}$ & $71.4 \%$ \\
\hline 9 & $\begin{array}{l}\text { Mam } \\
\text { a } \\
\end{array}$ & No & No & $\begin{array}{c}\mathrm{Ye} \\
\mathrm{s}\end{array}$ & $\begin{array}{c}\mathrm{Ye} \\
\mathrm{s}\end{array}$ & $\begin{array}{c}\mathrm{Ye} \\
\mathrm{s}\end{array}$ & $\begin{array}{c}\mathrm{Ye} \\
\mathrm{s}\end{array}$ & $\begin{array}{c}\mathrm{Ye} \\
\mathrm{s}\end{array}$ & $71.4 \%$ \\
\hline 10 & Babu & No & No & $\begin{array}{c}\mathrm{Ye} \\
\mathrm{s}\end{array}$ & $\begin{array}{c}\mathrm{Ye} \\
\mathrm{s}\end{array}$ & $\begin{array}{c}\mathrm{Ye} \\
\mathrm{s}\end{array}$ & $\begin{array}{c}\mathrm{Ye} \\
\mathrm{s}\end{array}$ & $\begin{array}{c}\mathrm{Ye} \\
\mathrm{s}\end{array}$ & $71.4 \%$ \\
\hline \multicolumn{10}{|c|}{ Ratio Kebenaran } \\
\hline
\end{tabular}

Pada Tabel 3.2 hasil rekaman web speech API dari beberapa kata yang diucapkan maka rasio kebenarannya adalah $85.7 \%$, kesalahan kata yang sering salah diterjemahkan oleh web tersebut adalah kata 'asi', 'papa', 'mama' dan babu. Gambar 5. adalah gambar bukti dari rekaman dari web speech API.

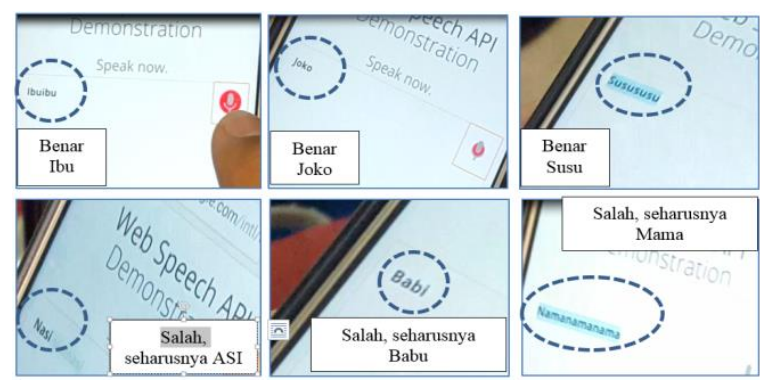

Gambar 5. Hasil Rekaman Web Speech API

Gambar 5. adalah gambar hasil dari rekaman web speech API, gambar diatas menjelaskan bahwasanya pada pengucapan kata Ibu, Joko, dan susu benar antara hasil ucapan dan teks yang muncul, sedangkan ada beberapa kata yang ucapannya dengan hasil teksnya tidak sesuai salah 
satunya ucapan 'asi' aktual teksnya adalah 'nasi', ucapan 'babu' aktual teksnya adalah 'babi', serta ucapan mama actual teksnya adalah 'nama'.

\section{KESIMPULAN}

Suara merupakan alat komunikasi paling mendasar bagi manusia. Dengan adanya suara kita dapat berkomunikasi antara manusia yang satu dengan yang lainnya. Dan dizaman tekhnologi seperti sekarang ini suara tidak hanya digunakan untuk komunikasi antar manusia tetapi juga digunakan untuk berkomunikasi dengan perangkatperangkat teknologi, oleh sebab itu topik pengenalan suara semakin berkembang. Penelitian yang dilakukan adalah untuk menyederhanakan pengenal ucapan yang bertujuan untuk mengenali pengaruh konsonan terhadap vokal dengan memanfaatkan informasi disekitar ucapan konsonan dan vokal tersebut. Hasil penelitian pengenalan pengaruh konsonan terhadap vokal dengan menggunakan MFCC(Mel-frequency cepstrum coefficients), dan klasifikasi datanya menggunakan clustering yang bertujuan untuk melihat kemiripan pengaruh konsonan terhadap vokal serta klasifikasi menggunakan SVM (support Vektor Machine) yang digunakan untuk menentukan akurasi pengaruh konsonan terhadap vokal ,Berdasarkan hasil penelitian, maka hasil yang didapat dari penelitian adalah sebagai berikut :

- Pengaruh konsonan terhadap vokaldari gambar frekuensi secara visual dapat dikenali dengan jelas dan adanya perbedaan setelah huruf vokal yang telah dipengaruhi konsonan.

- Data koefisien korelasi masing-masing pengaruh konsonan terhadap vokal adanya perbedaan, sehingga terbukti bahwasanya pengaruh konsonan terhadap vokal dapat dikenali.

- Kemiripan sinyal frekuensi dengan menggunakan metode clustering dapat terlihat adanya huruf vokal yang telah dipengaruhi oleh konsonan memiliki kemiripan

- Hasil prediksi dengan menggunakan SVM masih dibawah standard yang diharapkan.

- Menggunakan metode klasifikasi clustering dan SVM , semua dapat mengenali pengaruh konsonan terhadap vokal.

\section{DAFTAR PUSTAKA}

[1] Anil Kumar Vuppala, Saswat Chakrabarti, and K. Sreenivasa Rao, Effect of Speech Coding on Recognition of Consonant-Vowel (CV) Units 1G. S. Sanyal School of Telecommunications 2School of Information Technology Indian Institute of Technology Kharagpur Kharagpur 721302, West Bengal, India.

[2] Away, Gunaidi Abdia. 2006. MATLAB programming, Bandung:Informatika

[3] Arman, A.A. tahun 2004. Teknologi Kunci untuk Meningkatkan Cara Interaksi antara Manusia dengan Mesin.

[4] Aida-Zade, K.R., C. Ardil dan A.M. Sharifova. 2010. The Main Principles of Text-to-Speech Synresearch System. International Journal of Signal Processing 6.1

[5] Becchetti, Claudio dan Ricotti, Lucio Prina. 1999. Speech Recognition Theory and C++ Implementation. Chichester : John Willey \& Sons.

[6] Bradbury, Jeremy, Linear Predictive Coding, paper, 2002

[7] C. De Stefano, C. Sansone and M. Vento, Comparing Generalization and Recognition Capability of Learning Vector Quantization and Multi-LayerPerceptron Architectures, University of Naples, Napoli.

[8] Chou, Wu dan Juang, B. H., 2003. Pattern Recognition in Speech and Language Processing. Washington DC : CRC PRESS.

[9] D. T. Larose, An Introduction to Data Mining, Hoboken: John Wiley \& Sons Inc., 2005.

[10] 10.Gold, Ben, and Nelson Morgan, Speech and Audio Signal Processing :

[11] Processing and Perception of Speech and Music, John Wiley \& Sons, Inc., New York, 1999.

[12] 11. Ikuta, Hisatoshi, Yoshihisa Ishida, Takashi Honda, and Yasuhiko Arai, Spoken

[13] Word Recognition Using LVQ Based on DP Matching, Meiji

[14] University,Yokohama

[15] 12.Indrajaya, Yunes, Pemampatan Isyarat Tutur Menggunakan Penyandian

[16] Prediktif Linear, Jurusan Teknik Elektro Universitas Diponegoro, Tugas

[17] Akhir,2002.

[18] 13. John. G, and Dimitris G. Manolakis, Pemrosesan Sinyal Digital : Prinsip- prinsip, Algoritmadan Aplikasi, PT Prenhallindo, Jakarta, 1995.

[19] 14. Kusrini dan Luthfi, E. T. 2009. Algoritma Data Mining. Edisi 1. Andi Offset.

[20] Yogyakarta

[21] 15. May, Ignatius Leo, Pengenalan Vokal Bahasa Indonesia dengan Jaringan Saraf Tiruan melalui Transformasi Wavelet Diskret, Jurusan Teknik Elektro Universitas Diponegoro,Tugas Akhir, 2002.

[22] 16.Manunggal, H. S. (2005). Perancangan dan Pembuatan Perangkat Feature Lunak Pengenalan Suara Pembicara Dengan Menggunakan Analisa MFCC Extraction. Universitas Kristen Petra, Fakultas Teknologi IndustriJurusan Teknik Informatika. Surabaya, Indonesia: Tugas Akhir Strata 1.

[23] 17. Melissa, Gressia. Pencocokan Pola Suara (Speech Recognition) dengan FFT dan Algoritma DIVIDE and CONQUER.

[24] 18. M. J. Islam, Q. M. J. Wu, M. Ahmadi and M. A. SidAhmed, "Investigating the Performance of NaiveBayes Classifiers and K- Nearest Neighbor Classifiers," International Conference on Convergence Information Technology, pp. 1541-1546, 2007.

[25] 19. Philip Felber, speech recognition Illinois Institute of Technology Report of an Isolated Word experiment.

[26] 20. Pedoman Umum Ejaan yang disempurnakan / EYD oleh Menteri Pendidikan \& Kebudayaanberdasarkan surat keputusannya pada tanggal 12 Oktober 1972, No.156/P/1972(Amran Halim,Ketua) 
IT FOR SOCIETY, Vol. 03, No. 02

ISSN 2503-2224

[27] 21. Rabiner, Lawrence and Biing-Hwang Juang, Fundamentals of SpeechRecognition, PTR Prentince-Hall Inc., New Jersey, 1993.

[28] 22. Rabiner, Lawrence. 1989. A Tutuorial on Hidden Markov Model and Selected

[29] Application in Speech Recognition. vol. 77. no. 2. pp. 257-286. IEEE.
[30] 23. Rabiner, Lawrence. 1993. Fundamental of Speech Recognition. New Jersey :

[31] Prentice Hall.

[32] 24. Rabiner, Lawrence dan Juang, B. H., 1991. Hidden Markov Models for Speech

[33] Recognition. vol. 33. no.3.pp.251272.TECHNOMETER 